\title{
Track-Bridge Longitudinal Interaction of Continuous Welded Rails on Arch Bridge
}

\author{
Rong Chen, Ping Wang, and Xian-kui Wei \\ MOE Key Laboratory of High-Speed Railway Engineering, Southwest Jiaotong University, Chengdu 610031, China \\ Correspondence should be addressed to Ping Wang; swjtuwp@hotmail.com
}

Received 15 November 2012; Revised 2 March 2013; Accepted 2 March 2013

Academic Editor: Valentina E. Balas

Copyright (C) 2013 Rong Chen et al. This is an open access article distributed under the Creative Commons Attribution License, which permits unrestricted use, distribution, and reproduction in any medium, provided the original work is properly cited.

\begin{abstract}
Taking arch bridges, including deck, half-through, and through arch bridges (short for DAB, HTAB, and TAB) as examples, mechanics analysis models of longitudinal interaction between continuously welded rails (short for CWRs) and arch bridges are established. Based on the finite element method (FEM), the longitudinal interaction calculation software of CWR on arch bridges has been developed. Focusing on an HTAB, the tension, compression, and deflection conditions are calculated and analyzed. The results show that the mechanics analysis models of three types of arch bridges can truly reflect the real state of the structure; the calculation software can be used for systematic research of the CWR on arch bridge; as for HTAB, temperature difference of arch rib has a small effect on rail tension/compression, and arch bridge can be simplified as a continuous beam for rail tension/compression additional force calculation; in calculation of deflection conditions of HTAB, it is suggested that train loads are arranged on half span and full span and take the direction of load entering bridge into account. Additionally, the deflection additional force variation of CFST basket handle arch bridge is different from that of ordinary bridge.
\end{abstract}

\section{Introduction}

Over the years, continuous welded rail (CWR) was usually laid on common simply supported beams or continuous beam bridge structure in China [1-4]. Nevertheless, in recent years, with the continuous improvement of the bridge and CWR construction level, more and more railway bridges applied a special type of bridge structure. Among them, the more typical cases are the following three types of arch bridges (deck, half-through, and through arch bridges, referred to as DAB, HTAB, and TAB), cable-stayed steel truss bridge, and so forth. Compared with general simply supported beam and continuous beam bridge, these special forms of bridges can more effectively meet the height requirements of larger span and a smaller structure and better adapt to changes in the railway line terrain. Therefore, the special forms of bridge structures play an important role when the clearance limited or project investment increased due to the need of uplifting the elevation of railway line, especially when there are some special requirements in terms of aesthetics, art, and landscape coordination for the bridge structure, these special structures of bridges can give full play to the role that ordinary bridge is difficult to replace.

Up to now, the related technology of CWR on ordinary bridge structure is relatively mature. Many scholars have started researches on the mechanics problems of the railway bridge under the load of moving vehicles and have obtained a lot of valuable results, including the Green's functions method for both infinite and finite elastic structures $[5,6]$ and the modal analysis method $[7,8]$. Some scholars have developed a general-purpose computing software [9]. The design and calculation method of CWR on ordinary bridge have been specified in a specification [10]. However, it often requires a separate establishment of the computational model to conduct a special study of CWR on the special bridge structures. It will cost a lot of efforts and slow down design progress, so it is necessary to analyze the mechanical characteristics and establish a common computational model for different special bridge structures. In this way, designer can get the calculation results of longitudinal interaction 


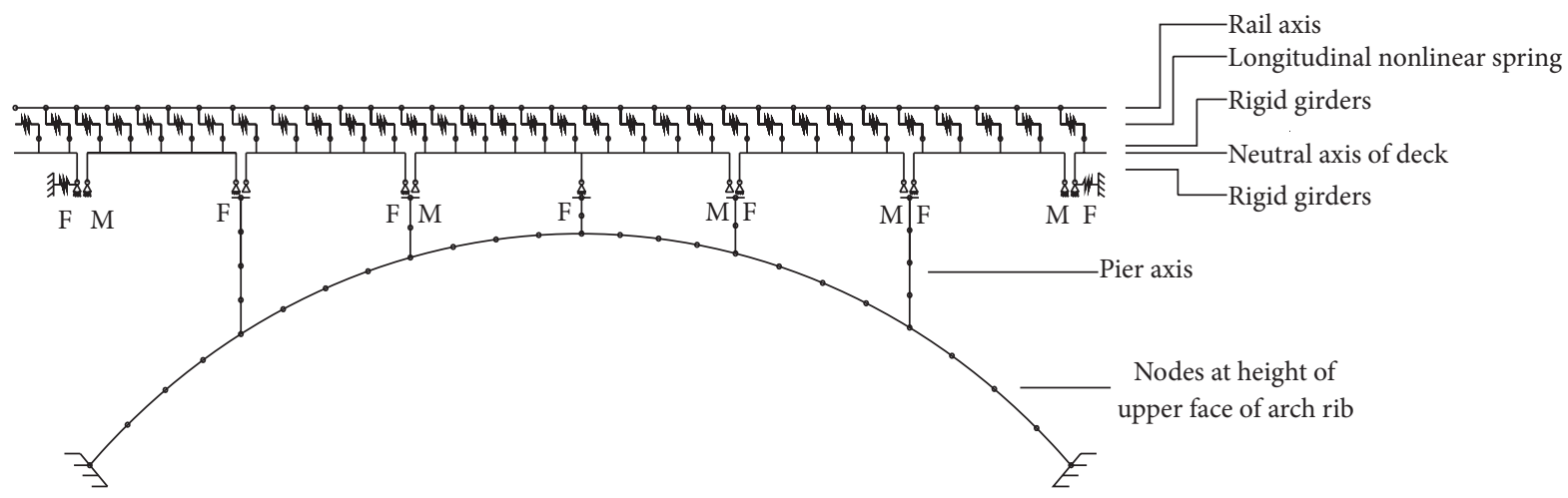

F: fixed bearing

M: movable bearing

FIGURE 1: The mechanics model of track/girder/pier of DAB.

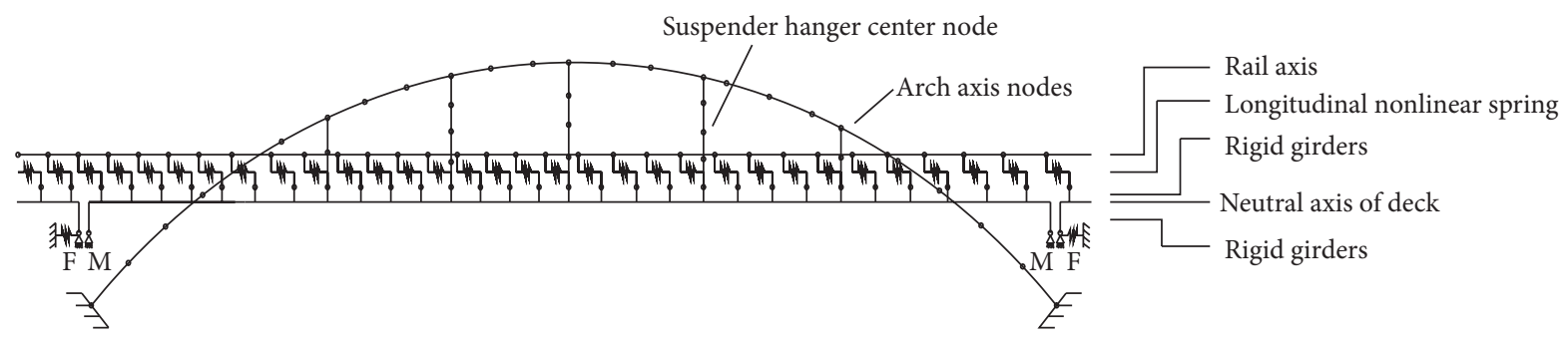

F: fixed bearing

M: movable bearing

FIgURE 2: The mechanics model of track/girder/pier of HTAB.

between CWR and special bridge through the modification of some key parameters. This paper focused on the longitudinal interaction of CWR on arch bridge, established an integrated model of track/bridge/pier for CWR on the deck, half-through, and through arch bridges, programmed the longitudinal interaction analysis software of CWR on arch bridge (LIACAB), and used this software to study the longitudinal force and deformation law to provide theoretical guidance for the design of CWR on the arch bridge.

\section{Longitudinal Interaction Model}

2.1. Basic Assumptions. Three types of arch bridges and ordinary bridge have common basic assumptions [11], which will not be elaborated in this paper. There are some other assumptions should be made for arch bridge. They are as follows:

(1) The arch foot and the underlying connection of DAB and $\mathrm{HTAB}$ are fully constrained, without considering underlying displacements.

(2) Lateral stiffness of arch ring structure is not considered, only considering vertical stiffness.

(3) For piers of DAB, only longitudinal stiffness is considered; pier's bottom and the upper arch ring are fixed together.
(4) Hangers of HTAB, TAB, and arch ring connected nodes are on the arch axis.

2.2. Mechanics Model. Essentially, analysis of CWR longitudinal force on bridge is based on the rail/beam interaction [8]. It is necessary to build realistic computational model to truly reflect the structure's stress state of special bridge structures. Track/girder/pier integrated computational model of three types of arch bridges is described below.

2.2.1. Model of Track/Girder/Pier of DAB. The mechanics model of DAB is shown in Figure 1. This type of bridge structure has the following features: the rail longitudinally interacts with top flange of girder through longitudinal railway track resistance; pier and lower flange of girder are connected to transmit the longitudinal force, vertical force, or moment; pier is connected with the arch rib to transmit force and bending moment. Mechanics model in Figure 1 is the true reflection of bearing state of this structure.

2.2.2. Model of Track/Girder/Pier of HTAB. The model of track/girder/pier of HTAB is shown in Figure 2. Features of this type of bridge structure are as follows: the rail longitudinally interacts with top flange of girder through longitudinal railway track resistance; the girder transmits longitudinal and 


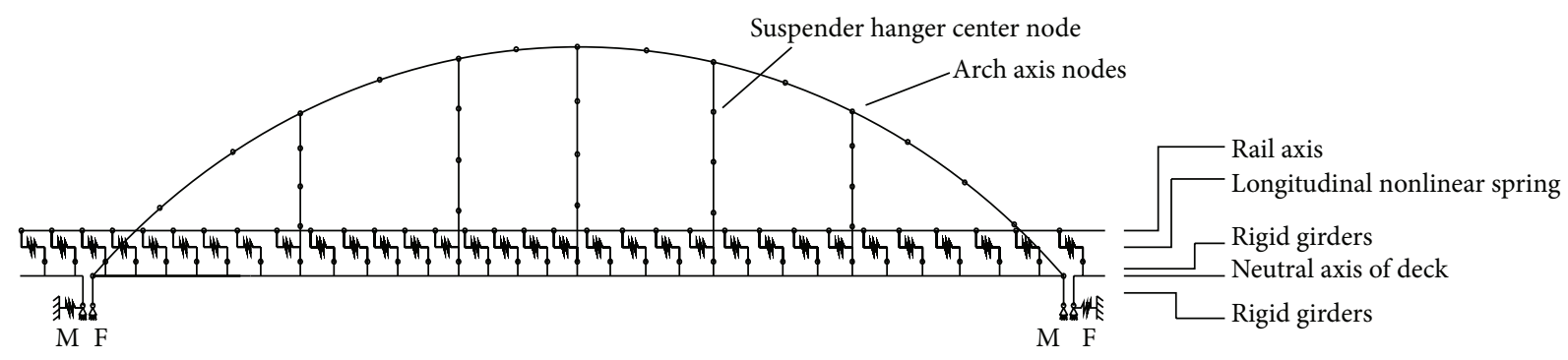

F: fixed bearing

M: movable bearing

FIgURE 3: The mechanics model of track/girder/pier of TAB.

vertical forces to the arch rib through pier or suspender; rail, girder, suspender, and arch rib form a coupled system of longitudinal interaction. Under different calculation conditions, each section has a unique balance point of force and deformation, so the forces and displacements of various parts can be obtained if the balance points are found.

\subsubsection{Model of Track/Girder/Pier of TAB. TAB is very com-} mon in the construction of urban rail transit. It is usually built to meet the needs of urban landscape and large span, generally divided into simple supported beam arch or continuous beam arch. Now TAB is often simplified into a normal simple supported beam or continuous beam in calculation. The calculation of longitudinal force and the results can meet the accuracy requirements. The mechanics model of track/girder/pier of TAB is shown in Figure 3. This type of bridge structure is similar to HTAB, but the difference is that the arch foot and the girder are connected together to form a structure of self-equilibrium system.

In these mechanics models, arch span and both ends of main arch can be made up with any number and the span of simply supported beams, continuous beams, or rigid frame bridge. And the entire girder can be considered as uniform section beam or beams with variable section. The horizontal stiffness of piers has embodied the pier structure type and its connection with girder at both ends of the main arch span. Piers and suspenders stiffness are reflected by their crosssection parameters. The types of arch rib structures, such as reinforced concrete arch, concrete filled steel tubular arch, steel box arch and steel truss arch, can be simplified as beam elements. Three arch axis line forms, such as the arc line, quadratic parabola, and catenary, are considered in these calculation models. Moreover, structure parameters and resistance type of track components are variable in the calculation model.

2.3. Element Selection. The calculation models of CWR on arch bridge mentioned above are established and solved by means of secondary development based on a large finite element software ANSYS. Reasonable element selection of the structural parts is particularly important to the calculation results, and the selections are as follows. (i) Rail: plane beam element BEAM3 is selected to simulate the rail instead of bar element LINK1; it may consider the influence of deck vertical deformation on the vertical deformation and force of rail.

(ii) Longitudinal resistance: simulated by nonlinear spring element COMBIN39.

(iii) Stiffness of piers and rail bearing points at both ends of main arch span: simulated by linear spring element COMBIN14.

(iv) Girder, arch, and pier of arch bridge: simulated by two-dimensional elastic cone asymmetric plane beam element BEAM54. BEAM54 is single axle and able to work under pressure and bending, 3 degrees of freedom on each node (along the $x$ - and $y$-axis displacement and rotation around the $z$-axis). The element allows asymmetric end face and end nodes to deviate from the section centroid location (see Figure 4). This feature can be used to establish the element nodes in the calculation model based on the actual bridge structure so as to accurately reflect the realistic structural state.

2.4. General-Purpose Computing Software. Most structures of the three types of arch bridges are similar, but the local structure is slightly different. This paper used the combined method of FORTRAN language, the finite element software ANSYS, and Parametric Design Language (APDL) to program the general-purpose computing software of longitudinal interaction of CWR track on arch bridge (LICAB). This software uses executable programs (by Fortran language) to read input parameters file and preprocess the data and uses source files compiled by APDL to read the relevant parameters of the arch bridge structure automatically. After that, it calculates a variety of conditions (including the conditions of tension/compression force, deflection force, the braking force, and the broken rail force) in ANSYS environment and generates the corresponding calculation results file. Figure 5 shows the three types of arch bridges established by LICAB.

LICAB's calculation results were compared with the results given in [12]. The comparison shows that the mechanics analysis models of three types of arch bridges can truly reflect the real state of the structure; the calculation software 


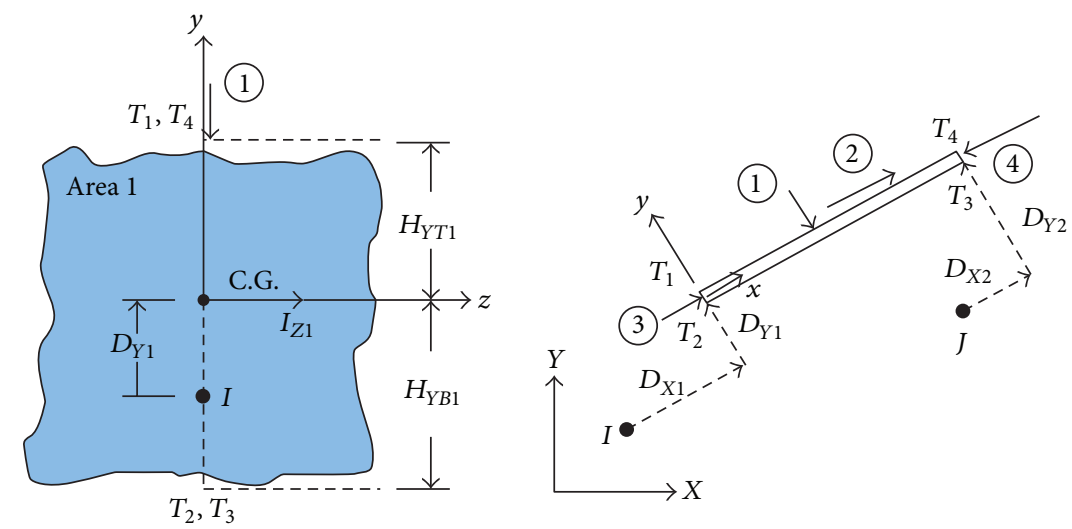

Figure 4: BEAM54 element.

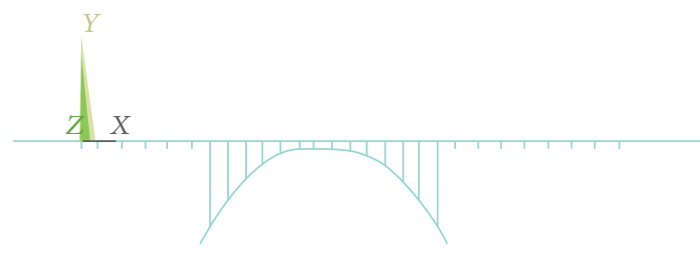

(a) Deck arch bridge

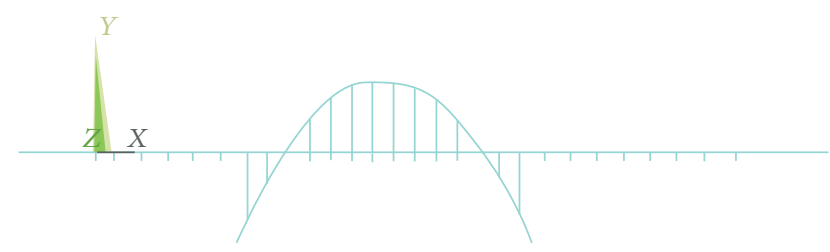

(b) Half-through arch bridge

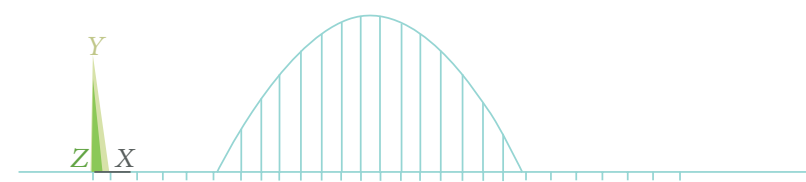

(c) Through arch bridge

FIGURE 5: Mechanics model of three types of arch bridges.

can be used for systematic research of the CWR on arch bridge.

\section{Engineering Case 1}

Here, taking the HTAB as an example, tension/compression and deflection conditions (the rail intensity control conditions) are analyzed.

3.1. Overview of Bridge Structure. A new double-track railway large span arch bridge: its main span is $351 \mathrm{~m}$, with a vector height of $64.5 \mathrm{~m}$; the arch axis is quadratic parabola, and 18 suspenders with spacing of $12 \mathrm{~m}$ are set. The span of side beam is $24.6 \mathrm{~m}$, and its arch rib has a structure of steel-concrete composite truss basket arch structure; its main span adopts the prestressed concrete box girder. Bridge span arrangement is shown in Figure 6.

3.2. Tension/Compression Condition. In calculation of tension/compression condition, beam temperature difference is $15^{\circ} \mathrm{C}$, and temperature difference of arch rib in turn is 0 , 15,20 , and $25^{\circ} \mathrm{C}$. Rail tension/compression additional force calculation results are shown in Figure 7.
In Figure 7, temperature difference of arch rib only has a small effect on rail tension/compression. This is primarily because the main girder's longitudinal deformation is centrosymmetrical, and the deformation of arch rib has little influence on it. Based on this, the HTAB can be simplified as a continuous beam model as shown in Figure 9. The comparative results of the two were shown in Figure 8.

Figure 7 shows the influence of temperature difference of the arch rib on rail tension/compression additional force is small, mainly because the longitudinal tension/compression deformation of main span under temperature difference effect is almost centrosymmetric, and the deformation of arch rib has no influence on the deformation of girder. Based on this point, the arch bridge can be simplified as a continuous beam whose fixed bearing is set in the middle of span for the tension/compression force condition. Figure 8 shows the rail tension/compression additional force result of the simplified method, which is almost identical to the results of accurate model. The calculation result of simplified method is slightly larger mainly because suspenders have some certain constraints on the main beam. From the design perspective, the simplified method is feasible and safer.

3.3. Deflection Condition. In calculation of deflection conditions, the train loads (Chinese live load) are separately 


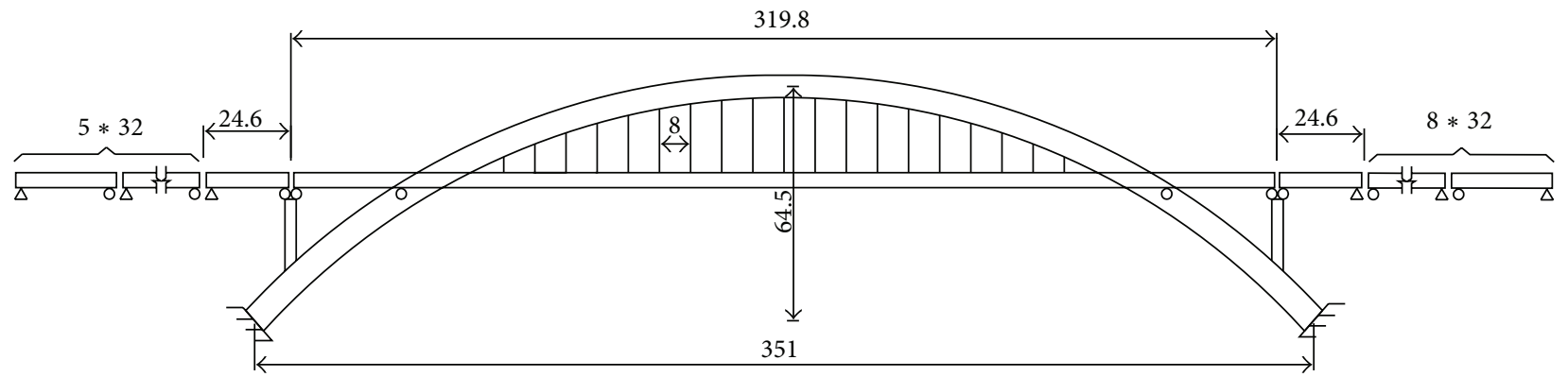

$\bigcirc$ Fixed bearing

$\triangle$ Sliding bearing

FIGURE 6: Span arrangement of bridge (unit: m).

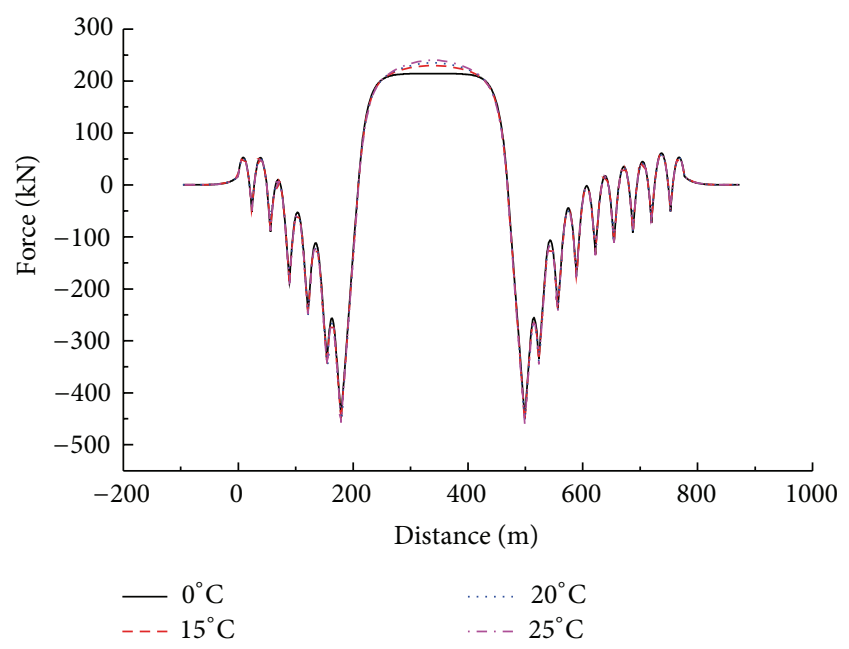

FIGURE 7: Rail tension/compression additional force results.

arranged on 1/4,1/2,3/4, and full span of arch bridge from the left side to the other side. Rail deflection force calculation results are shown in Figure 10.

Figure 10 shows that the peak of tensile stress appears at the left junction pier of the mail span when the train loads arranged on 1/2 span of arch bridge, and the peak of compressive stress appears at the left-side span's middle of main span. When the train loads are distributed uniformly on full span of bridge, rail's maximum tensile stress occurs near the right juncture pier, and the compressive stress peak appears at the middle of the right-side span. The results are obtained in the case of train load entering into bridge from one direction. So, it is reasonable to arrange train loads on $1 / 2$ span and full span and take the direction of load entering bridge into account.

\section{Engineering Case 2}

A long span concrete filled steel tubular (CFST) basket handle arch bridge is applied in newly constructed double-track railway. The calculated span is $380 \mathrm{~m}$, and the vector height of the bridge's arch ring is $76 \mathrm{~m}$. Within the vault height of

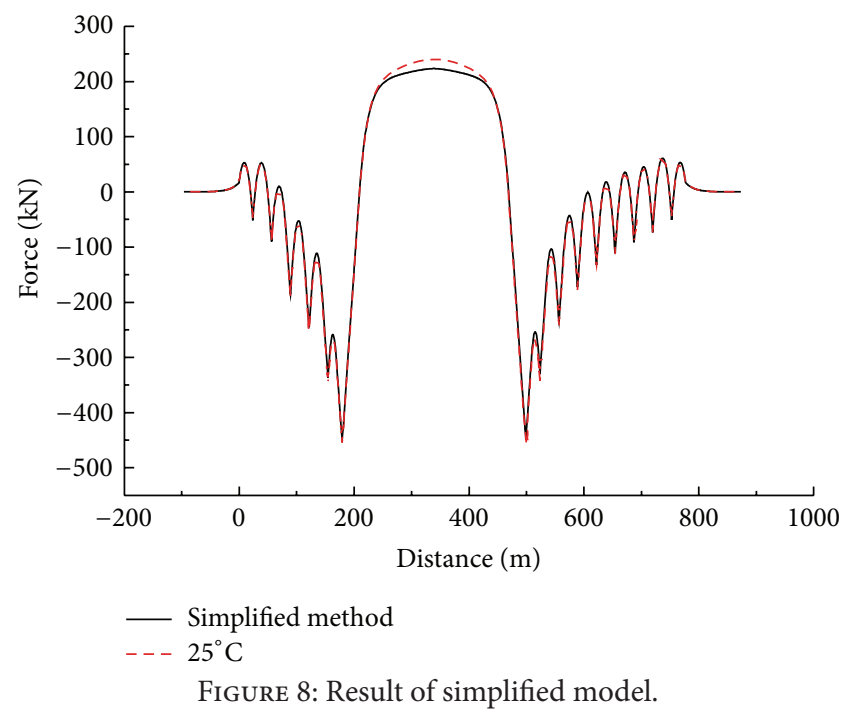

$77 \mathrm{~m}$, concrete rigid frame with type " $\Pi$ " is used; the beam on the arch outside the vault height $77 \mathrm{~m}, 32 \mathrm{~m}$ T-type simply supported girder is adopted; the column pier adopts steel tube concrete rigid frame pier (seen in Figure 11). On the bridge, the ballasted track with continuous welded rail is laid with normal resistance fasteners and without expansion rail joints.

For this model, it is assumed that the arch foot pier in the left is the origin of coordinates. In order to reduce the influence of boundary conditions, 6 spans from both sides of the arch ring center are taken as calculation sections according to the actual bridge arrangement.

4.1. Tension/Compression Condition. Existing specification only specifies the conventional beam temperature differences, not involving temperature difference values of bridges with special types. In calculation of expansion force, two conditions were considered, that is, the arch ring temperature difference and no arch ring temperature difference. The temperature difference of concrete beam is taken as $\pm 15^{\circ} \mathrm{C}$. The temperature difference of arch ring is considered as $\pm 15^{\circ} \mathrm{C}$. Figure 12 shows the result of rail tension/compression 


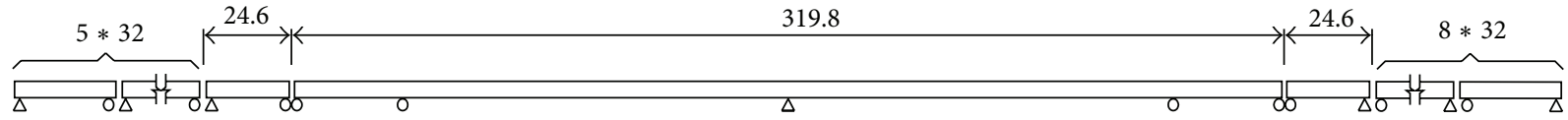

O Fixed bearing

$\triangle$ Sliding bearing

Figure 9: Simplified model of HTAB.

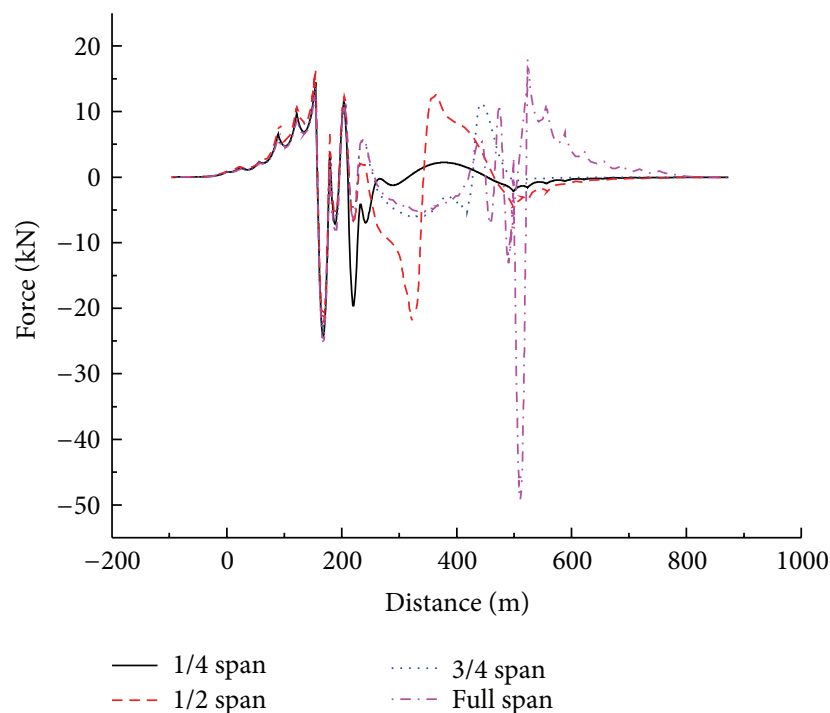

FIGURE 10: Rail deflection force calculations.

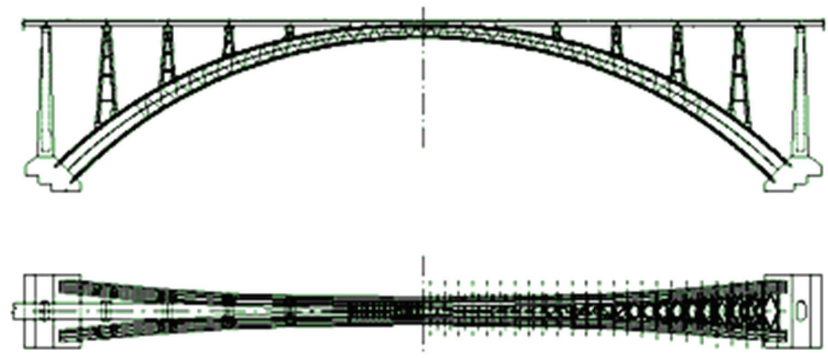

FIGURE 11: Bridge structure diagram.

additional force. Figure 13 shows the relative displacements between beam and rail.

As shown in Figures 12 and 13, when the temperature difference of the arch ring is considered, the maximum rail expansion additional force is $403.60 \mathrm{kN} / \mathrm{rail}$, and the maximal beam/rail relative displacement is $6.07 \mathrm{~mm}$. If the temperature difference of the arch ring is not considered, the maximum rail expansion additional force is $175.33 \mathrm{kN} / \mathrm{rail}$, and the maximal beam/rail relative displacement is $3.35 \mathrm{~mm}$.

4.2. Deflection Condition. China railway standard live load is used, and the load moves from left to right into the bridge. The calculation considers two load distributions, that is, the full-span load and a half-span load. The deflection additional

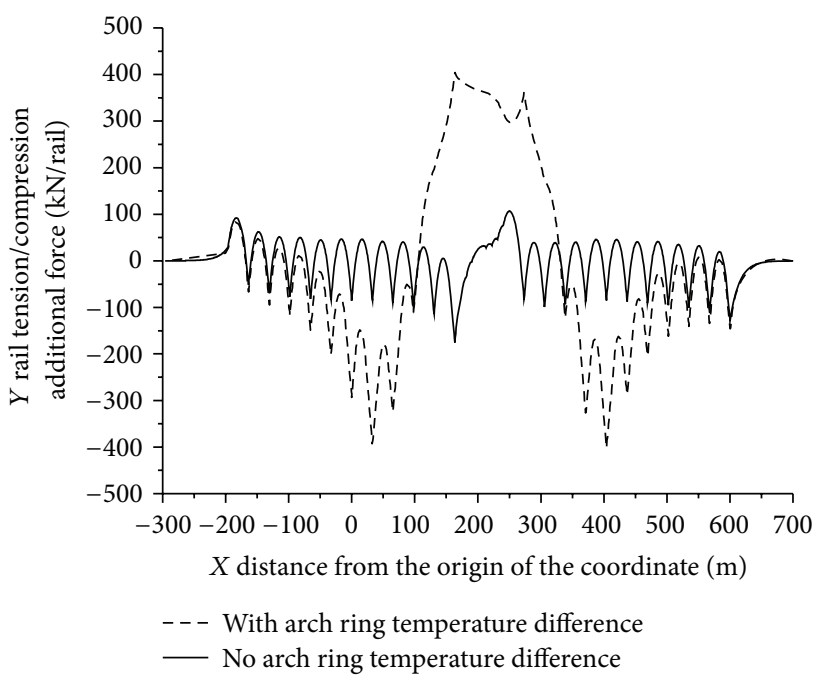

FIGURE 12: Rail tension/compression additional force.

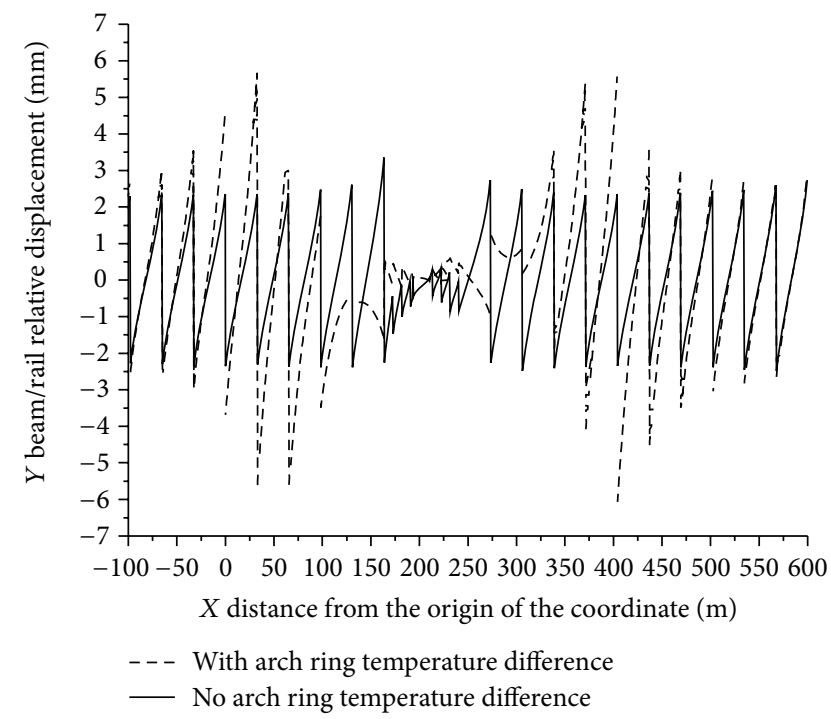

FIGURE 13: Beam/rail relative displacements.

force of rail result is shown in Figure 14. The beam/rail relative displacement is shown in Figure 15.

As seen from Figures 14 and 15, when there is full span load, the maximal deflection additional tension is $116.61 \mathrm{kN} / \mathrm{rail}$, and the maximal deflection additional pressure is $339.73 \mathrm{kN} /$ rail, maximal beam/rail relative displacement is 


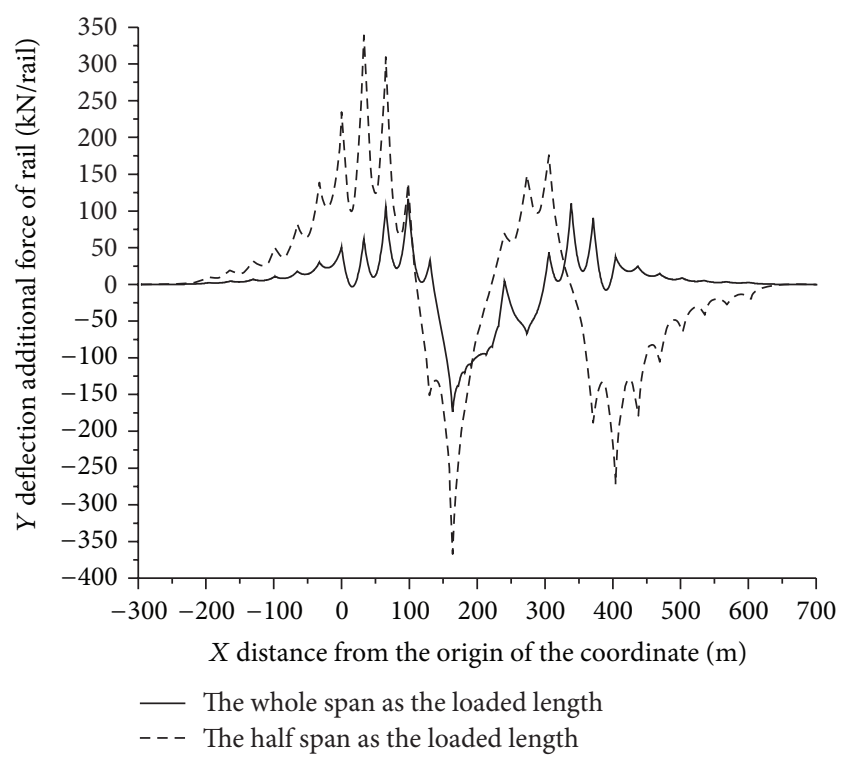

FIGURE 14: Rail deflection additional force.

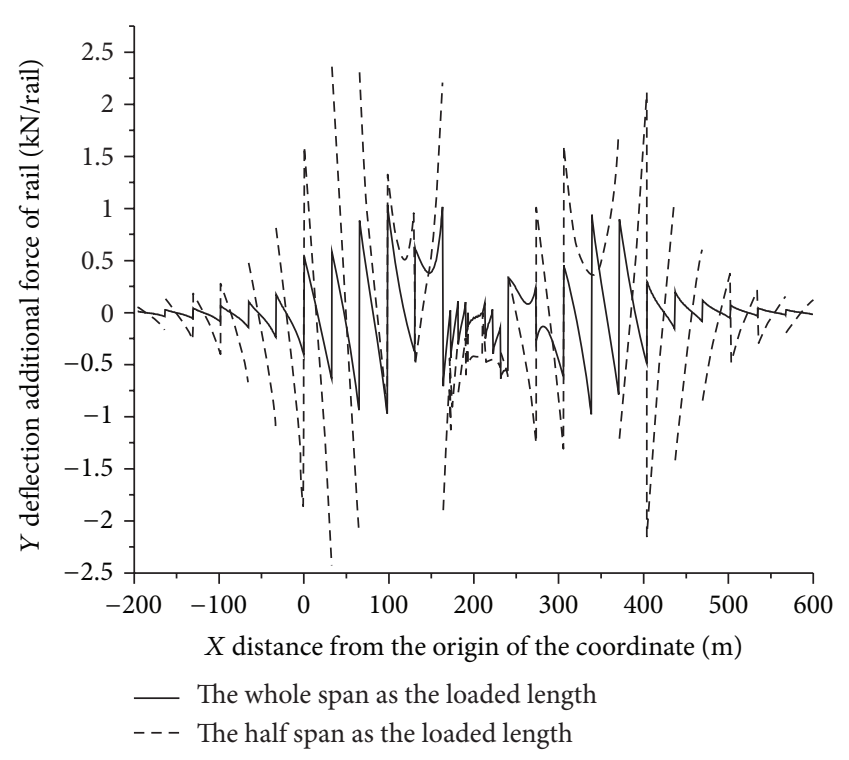

FIGURE 15: Beam/rail relative displacements.

$1.03 \mathrm{~mm}$. When there is half-span load, the maximal deflection additional tension is $339.73 \mathrm{kN} / \mathrm{rail}$; and the maximal deflection additional pressure is $367.37 \mathrm{kN} /$ rail; maximal beam/rail relative displacement is $2.43 \mathrm{~mm}$.

4.3. Braking Condition. China railway standard live load brakes from the left to the right into the bridge. The calculation considers two load distributions, that is, the full-span load and a half-span load. Figure 16 shows the braking additional force results of rail. The fast beam/rail relative displacement is shown in Figure 17.

As seen from Figures 16 and 17, when the braking load is distributed in full span, the maximal braking additional force is $179.57 \mathrm{kN} /$ rail, and the maximal beam/rail fast relative

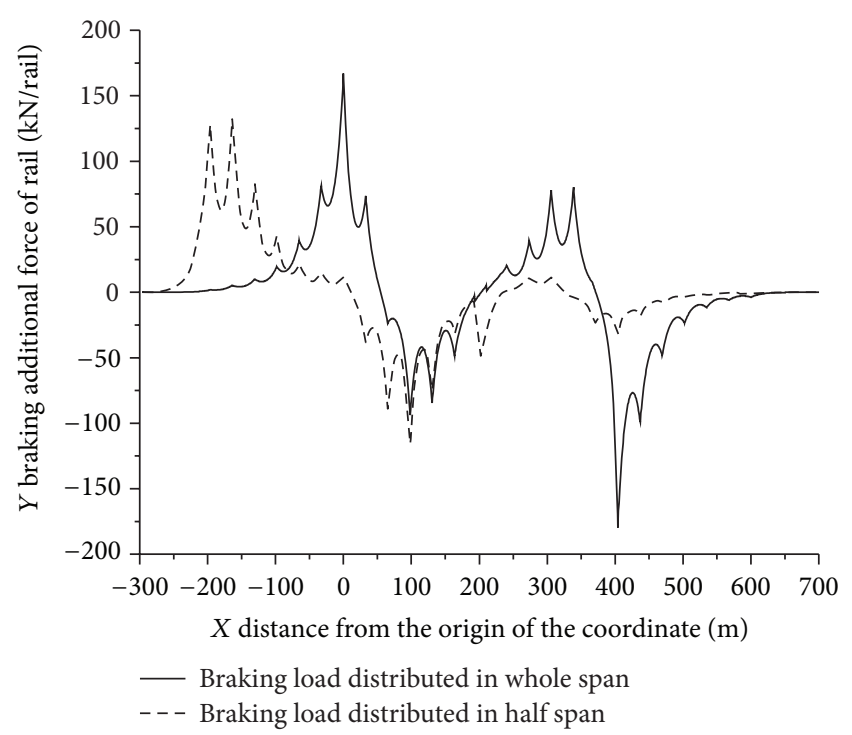

FIGURE 16: Rail braking additional force.

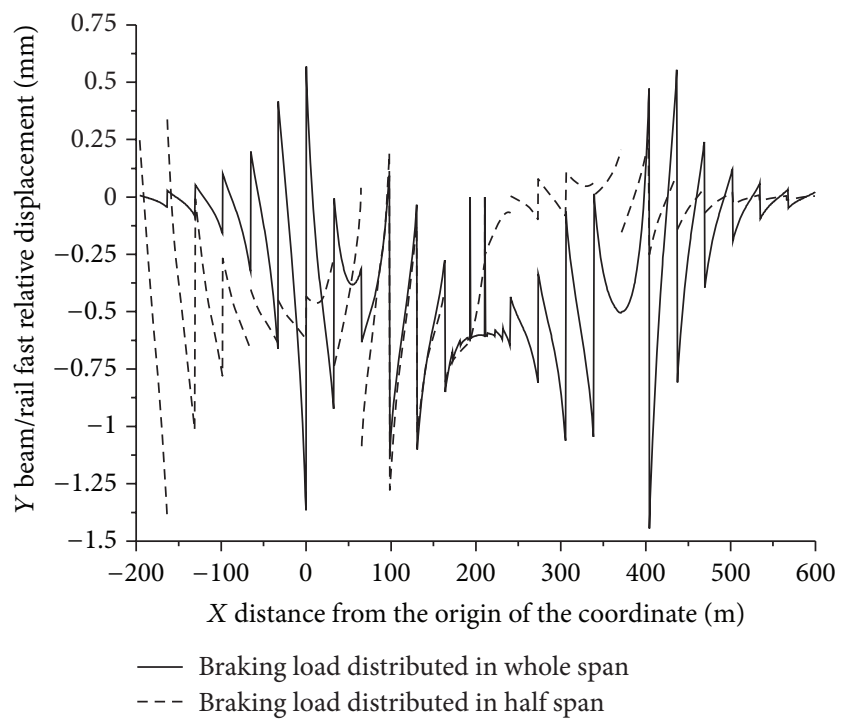

FIgURE 17: Beam/rail fast relative displacements.

displacement is $1.44 \mathrm{~mm}$. When the braking load is distributed in half span, the maximal braking additional force is $115.62 \mathrm{kN} / \mathrm{rail}$, and the maximal beam/rail fast relative displacement is $1.29 \mathrm{~mm}$.

4.4. Results Analysis. In tension/compression condition, the maximal rail expansion additional force is increased by 1.31 times when the temperature difference of arch ring is considered. The distribution of expansion additional force changed a lot, which means the temperature variation has a great influence on the stress of track structure.

The calculation results in deflection condition show that deflection additional force is small when the load is set on full span, because the deflection of arch ring is symmetric, and the beam/rail relative displacement is small. When the load 
is only set on half span, the arch ring occurred approximation anti-symmetric deformation, and the beam/rail relative displacement is big, which results in big deflection additional force.

In braking condition, the beam/rail fast relative displacement is big when the braking load is distributed in full span, and the results can be used in the stability checking calculation of ballast bed.

\section{Conclusions}

In summary, this paper analyzed the characteristics of CWR on arch bridges, created DAB, HTAB, and TAB mechanics analysis models, and developed the calculation software for longitudinal interaction of CWR on arch bridges (LICABs). Taking an HTAB as an example, the results can be concluded as follows:

(1) mechanics analysis models of three types of arch bridges can truly reflect the real state of the structure;

(2) using the LICAB software, systematic research can be realized for the force and deformation law of the CWR on arch bridge;

(3) as for HTAB, temperature difference of arch rib has a small effect on rail tension/compression, and arch bridge can be simplified as a continuous beam for rail tension/compression calculation;

(4) it is suggested that train loads are arranged on $1 / 2$ span and full span and take the direction of load entering bridge into account in calculation of deflection conditions of HTAB;

(5) the deflection additional force variation of CFST basket handle arch bridge is different from that of ordinary bridge. The deformation of arch ring has big influence on the deflection additional force of rail. Usually, when the load is set on half of the span, the deflection additional force is the worst. For ordinary bridge, its deflection additional force is much less than the tension/compression additional force, so it is not used as the controlling factor. But the deflection additional force of the basket handle arch bridge is big, close to the tension/compression additional force, so attention should be paid to its check calculation.

\section{Acknowledgments}

This work is financially supported by the National Natural Science Foundation of China under Grant no. 51078320 and no. 51008256. And it was also supported by the Scientific Research and Development Program of Chinese Ministry of Railways under Grant no. $2011 \mathrm{G} 009$.

\section{References}

[1] L. Fryba, "Thermal interaction of long welded rails with railway bridges," Rail International, vol. 16, no. 3, pp. 5-24, 1985.
[2] J. Z. Jiang, "Additional longitudinal forces in continuously welded rails and their transmission on railway bridges," China Railway Science, vol. 19, no. 2, pp. 67-75, 1998.

[3] Q. Y. Xu, Static and dynamic 3D finite element analysis of additional longitudinal forces transmission between CWR and highspeed railway bridges [Doctoral Dissertation], Central South University, Changsha, China, 2005.

[4] C. B. Cai, "Calculation of additional longitudinal forces in continuously welded rails on supper-large bridges of high-speed railways," Journal of Southwest Jiaotong University, vol. 38, no. 5, pp. 609-614, 2003.

[5] T. Mazilu, "Interaction between a moving two-mass oscillator and an infinite homogeneous structure: green's functions method," Archive of Applied Mechanics, vol. 80, no. 8, pp. 909927, 2010.

[6] A. V. Pesterev, C. A. Tan, and L. A. Bergman, "A new method for calculating bending moment and shear force in moving load problems," Journal of Applied Mechanics, Transactions ASME, vol. 68, no. 2, pp. 252-259, 2001.

[7] J. Li and M. Su, "The resonant vibration for asimply supported girder bridge under high-speed trains," Journal of Sound and Vibration, vol. 224, no. 5, pp. 897-915, 1999.

[8] P. Lou, "Vertical dynamic responses of a simply supported bridge subjected to a moving train with two-wheelset vehicles using modal analysis method," International Journal for Numerical Methods in Engineering, vol. 64, no. 9, pp. 1207-1235, 2005.

[9] X. K. Wei, X. P. Chen, and P. Wang, "Ballasted track calculation software development and application of CWR on bridge," Railway Construction, no. 8, pp. 115-118, 2010.

[10] China's Ministry of Railways, Continuously Welded Rail Track Design Code (Approval Review), China Railway Publishing House, Beijing, China, 2007.

[11] Z. Y. Guang and H. A. Gao, Continuously Welded Rail Track, China Railway Publishing House, Beijing, China, 2005.

[12] ANSYS, Theory Reference. ANSYS Release 9. 0, 2004. 


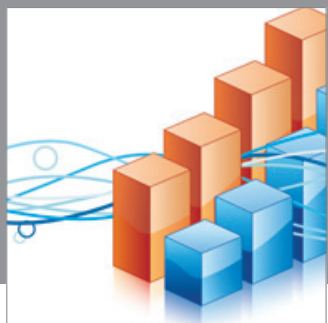

Advances in

Operations Research

mansans

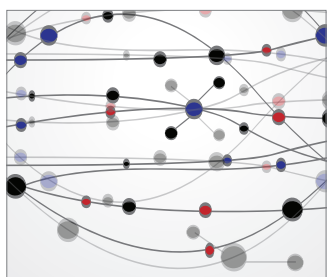

The Scientific World Journal
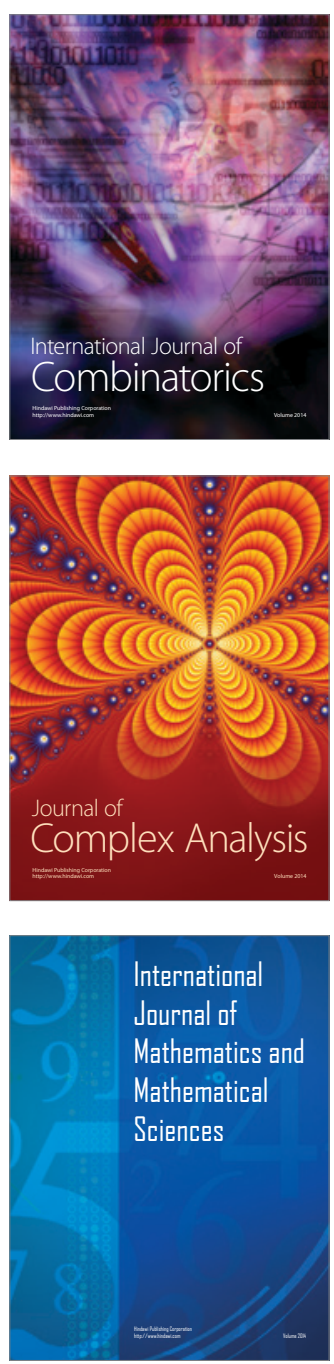
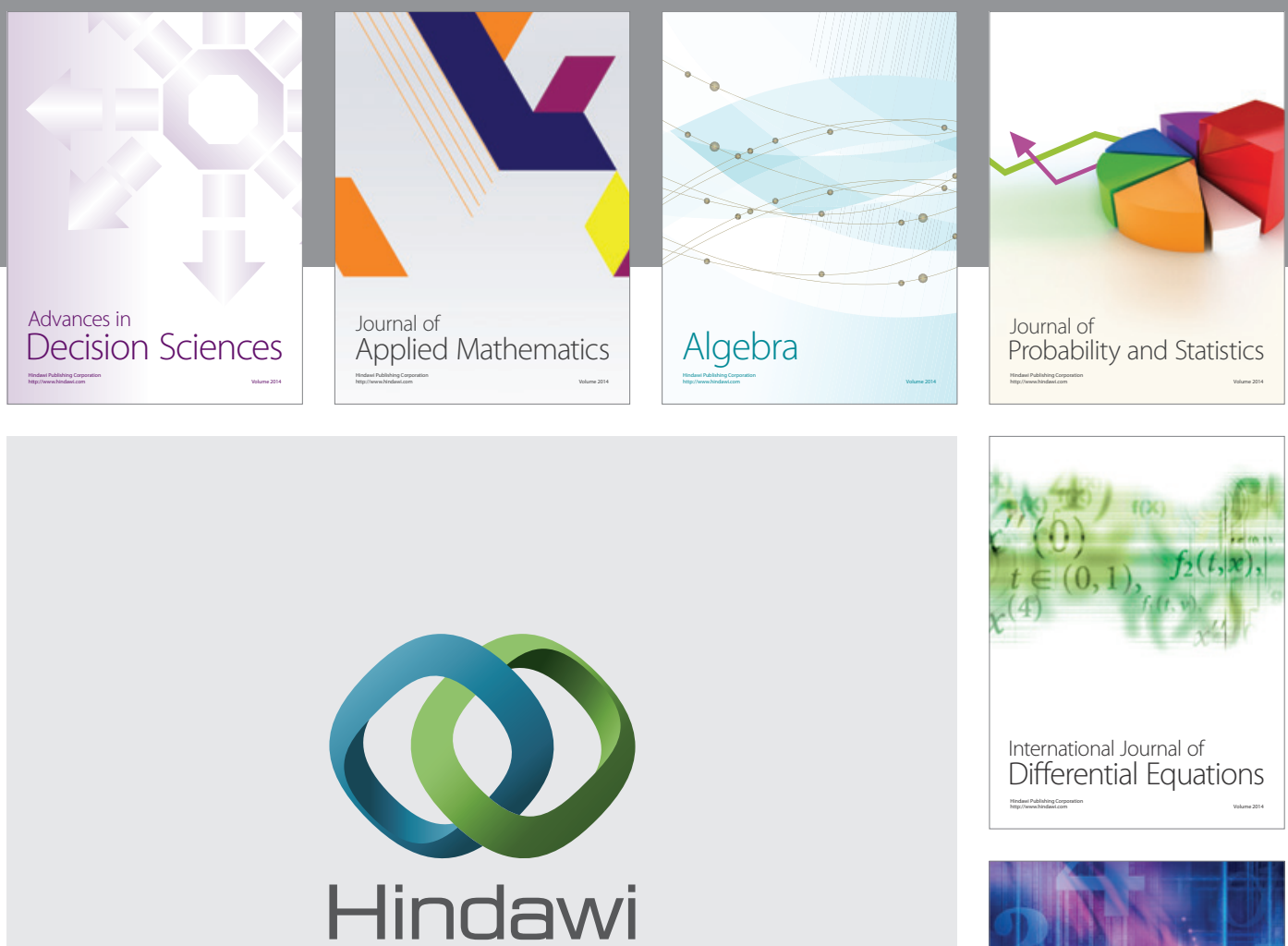

Submit your manuscripts at http://www.hindawi.com
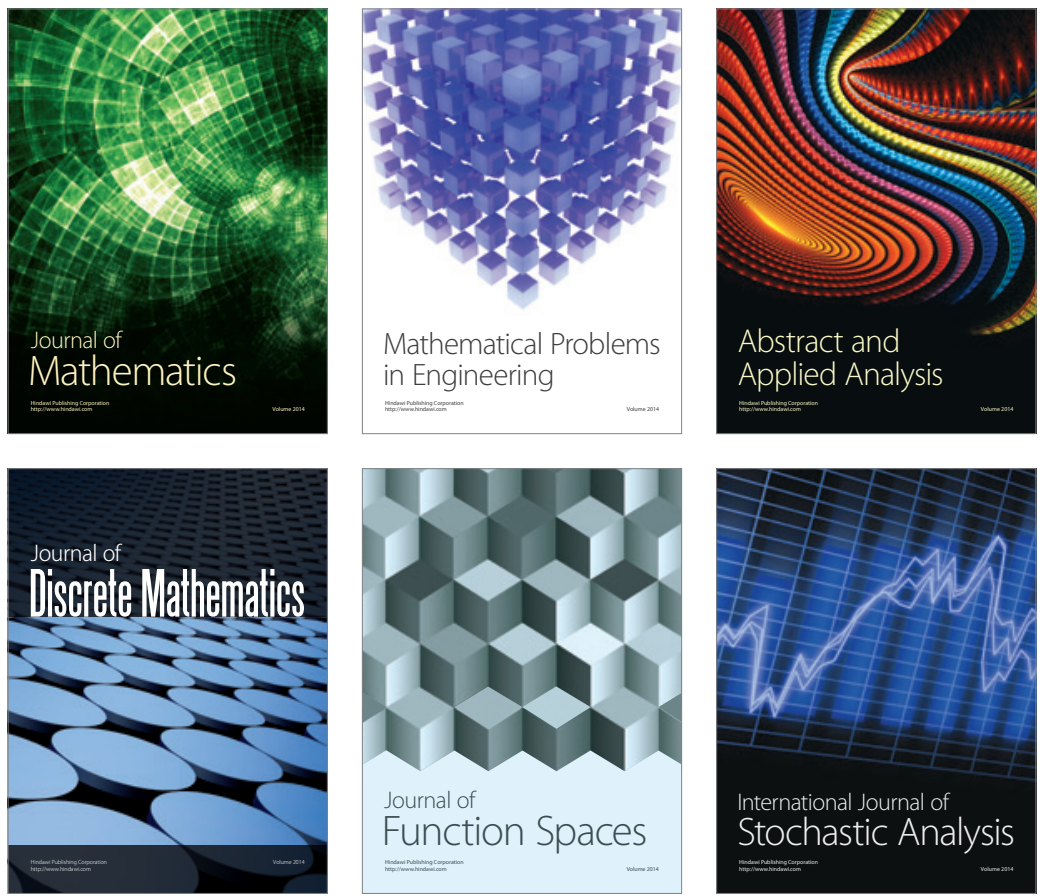

Journal of

Function Spaces

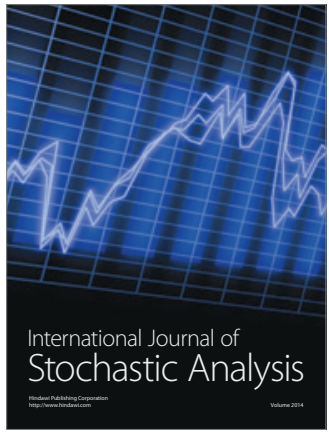

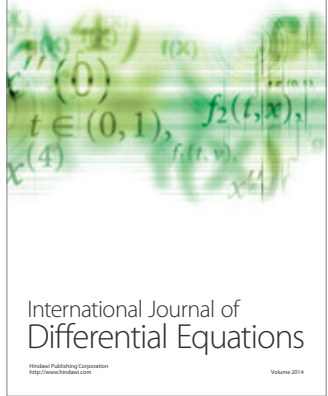
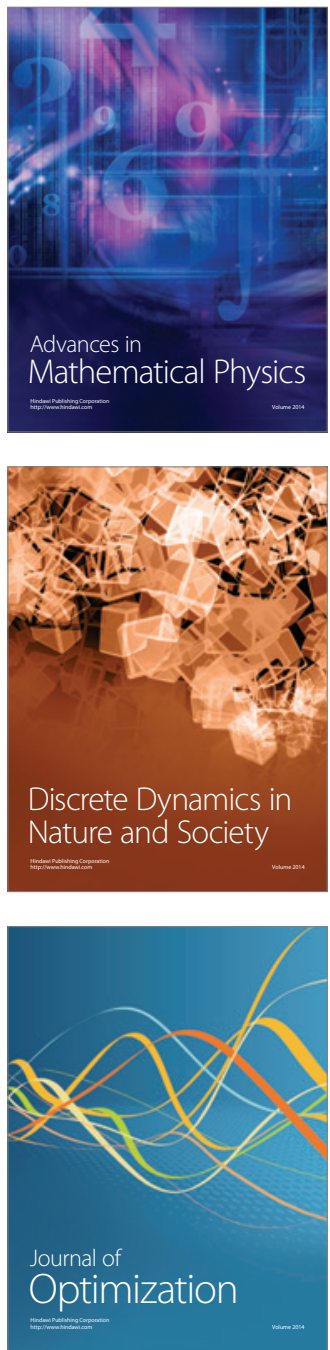